\title{
Predictors of Co-Occurring Substance Use among Asian Americans in Residential Treatment Programs
}

\author{
Minjeong Kim¹, Jinhee Lee ${ }^{2}$, Midori Nakajima3 ${ }^{3}$ Linda Chafetz ${ }^{3}$ \\ ${ }^{1}$ School of Nursing, San Diego State University, San Diego, USA \\ ${ }^{2}$ School of Nursing, California State University-East Bay, Hayward, USA \\ ${ }^{3}$ University of California-San Francisco, San Francisco, USA \\ Email: minjeong.kim@sdsu.edu
}

How to cite this paper: Kim, M., Lee, J., Nakajima, M. and Chafetz, L. (2019) Predictors of Co-Occurring Substance Use among Asian Americans in Residential Treatment Programs. Open Journal of Psychiatry, 9, 153-164.

https://doi.org/10.4236/ojpsych.2019.92012

Received: January 10, 2019

Accepted: April 20, 2019

Published: April 23, 2019

Copyright $\odot 2019$ by author(s) and Scientific Research Publishing Inc. This work is licensed under the Creative Commons Attribution International License (CC BY 4.0).

http://creativecommons.org/licenses/by/4.0/

\begin{abstract}
Although severe and chronic mental disorders are common among Asian Americans in residential treatment programs, little has been known about the prevalence and predictors of co-occurring substance use in this population. The purpose of this study was to examine predictors of co-occurring substance use among Asian Americans with mental disorders in residential treatment programs. This cross-sectional study included 375 clinical records of Asian Americans from residential treatment programs between 2007 and 2011. Demographic variables, principal psychiatric diagnoses, and data on alcohol, stimulant, and marijuana use were obtained from the clinical records. Separate binary logistic regression analyses were used to examine the demographic and diagnostic contributions to the risk of each type of substance use. Findings of this study indicated that the prevalence of co-occurring substance use was about 53\% in Asian Americans with mental disorders. Binary logistic regression analyses revealed that male gender, older age, and depressive disorder predicted more alcohol use, but homelessness and schizophrenia predicted less alcohol use. Male gender, homelessness, and smoking predicted more stimulant use. Male gender and younger age predicted more marijuana use. Based on the findings of this study, awareness about co-occurring substance use problems of ethnic minority psychiatric clients should be increased and appropriate substance use prevention and treatment programs should be developed and provided for high-risk groups.
\end{abstract}

\section{Keywords}

Asian Americans, Mental Disorders, Substance Use 


\section{Introduction}

The US Asian American population grew by 43\% between 2000 and 2010, compared to a 9.7\% growth in the general population, making Asian Americans the fastest growing racial group [1]. Asian Americans are projected to constitute $6.5 \%$ of the US population by 2025 , and $9.3 \%$ by 2050 [2]. The Asian American population is a heterogeneous group that includes at least 43 ethnic subgroups with different languages and dialects, immigration histories, religious beliefs, socioeconomic statuses, and traditional patterns for seeking health care. These social and cultural differences among Asian Americans may affect their psychiatric clinical manifestations, severity of mental health problems, access to health care, and treatment compliance and outcomes [2].

Overall, the reported prevalence of mental illness is lower in the Asian American adult population compared to other ethnic groups [3]. Despite the lower risk of mental illness among Asian Americans, it is still important to investigate because recent studies have shown that Asian American patients were admitted to the San Francisco Psychiatric Emergency Services twice as frequently as European and Latino/a Americans. They showed significantly higher functional impairment based on their Global Assessment Functioning (GAF) scores [4]. In addition, a prevalence study showed that schizophrenia and psychotic disorders, which are severe and chronic types of psychiatric disorders, are more common among Asian American veterans than among African American and Latino/a veterans [5].

Substance use studies have shown that Asian Americans are less likely to use substances and have a lower severity of drug use than European Americans [6] [7]. Of Asian Americans, Filipino/a Americans were reported to have the highest prevalence of substance use and cigarette smoking [8] [9]. Japanese Americans were found to have the highest number of alcohol related problems and binge-drinking episodes, followed by Filipino and Multi-Asian Americans including Korean and Chinese [10]. Substance use within the Asian American population has largely been ignored, mainly due to the popularity of the model minority theory which paints Asian Americans as the exemplary racial/ethnic group, thus minimizing the perceived severity of the problems [7]. Often, it is considered shameful within Asian cultures to have a family member with a mental illness or substance use problem, resulting in familial pressures to avoid seeking proper treatment [11] [12]. Substance dependent Asian Americans have already been shown to underutilize available programs and treatment when compared to European Americans [12] [13]. Park, Shibusawa, Yoon, \& Son [14] found that the majority of Chinese Americans and Korean Americans referred to such treatment by the legal system denied having alcohol problems. Only five percent of the sample admitted to having alcohol problems. Very few of them had ever heard about the Alcoholics Anonymous program and none of them had ever attended the program. Similar results were found in another study that showed that Asian Americans utilized legal services more frequently than medi- 
cal and psychiatric services related to their alcohol and drug use problems [7].

Co-occurring substance use in persons with mental disorders is a common issue. About $18.5 \%$ of the adults with mental disorders met the criteria for substance use disorders, whereas only $5 \%$ of the adults without mental disorders met the criteria for substance use disorders [3]. According to a recent epidemiology study, the prevalence of lifetime co-occurring substance use and mental disorder was about 7\% [15]. Specific psychiatric diagnoses related to substance use have been explored. Depressive disorder was significantly related to higher rates of alcohol, stimulant, and opiate use, whereas schizophrenia and schizoaffective disorder were significantly related to lower rates of alcohol, opiate, and polysubstance use [16] [17]. In another national 10-year longitudinal survey, persons with major depression, anxiety disorder, and disruptive behavior disorder were at a significantly greater risk to start using illicit drugs during the follow-up period [18]. Although there were subgroup psychiatric diagnostic differences regarding the prevalence of substance use, persons with mental disorders generally showed a higher prevalence of substance use.

However, little has been done to study the coexistence of mental illness and substance use in the rapidly growing Asian American population. A study found a positive association between having a psychological disorder and substance use disorder in Latino/a and Asian American adults from the National Latino/a and Asian American Study data, 2001-2003 [19]. A positive association between depressive symptoms and alcohol and illicit drug use has been reported in a study with a small sample size of college students [20]. Higher rates of suicidal ideation/attempts and lifetime generalized anxiety disorders among female heavy drinkers have also been identified in a study with a small sample size [21].

Until now, demographic risk factors related to substance use have been identified in Asian American studies. In most studies, males were more likely to have substance use [22] and alcohol-related problems [10]. Males were found to have a 12-month prevalence of substance use disorders eight times higher than females, but binge drinking was found to be comparable between males and females [21]. Youth between 18 - 25 years old were at five times the risk of alcohol use compared to middle and older age adults [9]. In particular, Southeast Asian American adults between 25 - 44 years old reported alcohol use comparable to the national percentage, although a lower risk of substance use of Asian Americans has been previously reported [22]. Mental illness is tied to socioeconomic status. YM Lee and K Holm [23] reported that among elderly Korean immigrants, a negative correlation existed between their income and depression scale score, which is consistent with findings from another study [19]. Smoking is a predictor of binge drinking among Asian Americans [24]. DE Toleran, PD Tran, B Cabangun, J Lam, RS Battle and P Gardiner [9] also found that among adult males in the San Jose, Daly City, and San Francisco criminal justice systems, a positive correlation existed between tobacco (not including cigarettes) and substance use. 
A limited amount of studies has investigated the prevalence and predictors of co-occurring alcohol, stimulant, and marijuana use among residential treatment program users, specifically Asian Americans. Therefore, the purpose of this study was to examine predictors of co-occurring alcohol, stimulant, and marijuana use among Asian Americans who receive residential treatment services.

\section{Methods}

\subsection{Study Design}

This study used a retrospective cross-sectional design using data obtained from clinical records from residential mental health treatment programs in California. The data source was from the Primary Health Care for the Mentally Ill Adults (Principal Investigator: Dr. Chafetz). This study was approved by the Committee on Human Research, University of California-San Francisco (UCSF).

\subsection{Sample and Setting}

This study included 375 Asian American patients in the San Francisco Bay Area. Patients were selected if he or she met the following criteria: 1) self-identified as an Asian American; 2) at least 18 years old; 3) had at least one psychiatric disorder; and 4) used residential treatment services provided by the San Francisco Progress Foundation between 2007 and 2011. Exclusion criteria were: 1) not self-identified as an Asian American; 2) under 18 years old; 3) had no psychiatric disorder; and 4) never used residential treatment services provided by the San Francisco Progress Foundation between 2007 and 2011.

The settings were 11 residential treatment programs for patients with psychiatric disorders operated by the San Francisco Progress Foundation in the San Francisco Bay area, California. These programs offer acute residential services that provide alternatives to hospitalization as well as a continuum of transitional residential programs including special programs for long-term patients and the elderly. Clinical faculty at the UCSF School of Nursing provide integrated primary care in these settings as a faculty outreach practice.

\subsection{Data Collection}

Data were extracted from clinical records completed by Nurse Practitioners (NPs) during the study period. Variables included age (younger (18 - 35 years old), middle (35 - 50 years old), and older ( $>50$ years old)); gender (male vs. female); living condition (homeless on the streets or in shelters vs. other housing); insurance type (insured vs. uninsured); and smoking status (current smoker vs. non-smoker). Principal psychiatric diagnoses which represent the main reason for admission were used for this study. Classifications included schizophrenia, schizoaffective disorder (SAD), bipolar disorder, depressive disorder, anxiety disorder, psychosis not other specified (PNOS), and other minor psychiatric disorders (personality disorders, etc.). Substance use which is a dependent variable in this study, was noted as yes/no for alcohol, stimulant, and marijuana use 
(currently using or used within 30 days prior to entering the residential treatment program).

\subsection{Data Analyses}

Descriptive statistics were used to examine sample characteristics, including frequencies and percentages for all categorical variables. As preliminary analyses, Chi-square tests were computed between patients' alcohol, stimulant, and marijuana use and all demographic and independent variables. Variables showing a significant relationship to alcohol, stimulant, and marijuana use were included in the final binary logistic regression analyses. Significance level was set at an alpha level of 0.05 in all analyses. The SPSS 21 version program was used to analyze data in this study.

\section{Results}

The sample included 375 Asian Americans (Table 1). About 46.7\% were males and 53.3\% were females. About $36.5 \%$ fell into the younger age group (18 - 35 years old), $40.3 \%$ into the middle age group (35 - 50 years old), and $23.2 \%$ in the older age group ( $>50$ years old). Approximately $37 \%$ of the sample was homeless and $80 \%$ of the sample had insurance. About $57 \%$ of the sample was current smokers. In terms of psychiatric diagnoses, about $62.7 \%$ of the sample was diagnosed with schizophrenia or schizoaffective disorder, followed by depressive disorder (14.9\%) and bipolar disorder (11.2\%). Very few were diagnosed with anxiety disorder (3.7\%), PNOS (3.2\%), and other minor psychiatric diagnoses (4.3\%). About $52.8 \%$ of the sample was co-occurring substance users. About $36.3 \%$ of the sample was alcohol users, $33.1 \%$ was stimulant users, and $25.6 \%$ was marijuana users.

Table 2 shows the findings for predictors of each alcohol, stimulant, and marijuana use. Firstly, six predictors explained $31 \%$ to $43 \%$ of the total variance in alcohol use $\left(\chi^{2}(d f)=121(7), p<0.001\right)$. Males had a significantly increased risk of alcohol use 5.4 times (95\% CI: 2.83, 10.40) higher than females. Depressive disorder also significantly increased the risk of alcohol use 5.3 times (95\% CI: $2.37,12.01)$ more than other psychiatric diagnoses. On the contrary, younger age $(O R=0.33,95 \%$ CI: $0.15,0.72)$ and middle age $(O R=0.45,95 \%$ CI: $0.21,0.94)$ significantly decreased the risk of alcohol use compared to the older age group. Homelessness $(O R=0.38,95 \%$ CI: $0.20,0.71)$ and schizophrenia $(O R=0.22$, $95 \%$ CI: $0.11,0.44)$ also significantly decreased the risk of alcohol use. For stimulant use, $24 \%$ to $34 \%$ of the total variance was explained by six predictors $\left(\chi^{2}(d f)=88(7), p<0.001\right)$. Males have a significantly increased risk of stimulant use 6.5 times (95\% CI: 3.49, 12.07) higher than females. Homelessness $(O R=4.5$, $95 \%$ CI: $2.33,8.81)$ and smoking ( $O R=2.8,95 \%$ CI: $1.33,5.74)$ also significantly increased the risk of alcohol use. For marijuana use, $26 \%$ to $38 \%$ of the total variance was explained by four predictors $\left(\chi^{2}(d f)=113(5), p<0.001\right)$. Males had a significantly increased risk of marijuana use 8.4 times $(95 \%$ CI: $4.48,15.9)$ higher 
Table 1. Sample characteristics of Asian Americans in residential treatment programs $(N=375)$.

\begin{tabular}{|c|c|}
\hline Variable & $n(\%)$ \\
\hline \multicolumn{2}{|l|}{ Gender } \\
\hline Male & $175(46.7)$ \\
\hline Female & $200(53.3)$ \\
\hline \multicolumn{2}{|l|}{ Age } \\
\hline $18-35$ & $137(36.5)$ \\
\hline $35-50$ & $151(40.3)$ \\
\hline$>50$ & $87(23.2)$ \\
\hline \multicolumn{2}{|l|}{ Living condition } \\
\hline Honelessness & $139(37.1)$ \\
\hline Others & $236(62.9)$ \\
\hline \multicolumn{2}{|l|}{ Insurance } \\
\hline Insured & $256(79.8)$ \\
\hline Uninsured & $65(20.2)$ \\
\hline \multicolumn{2}{|l|}{ Smoking } \\
\hline Smoker & $197(56.6)$ \\
\hline Non-smoker & $151(43.4)$ \\
\hline \multicolumn{2}{|l|}{ Psychiatric disgnosis } \\
\hline Schizophrenia & $121(32.3)$ \\
\hline Schizoaffective disorder (SAD) & $114(30.4)$ \\
\hline Depressive disorder & $56(14.9)$ \\
\hline Bipolar disorder & $42(11.2)$ \\
\hline Anxiety disorder & $14(3.7)$ \\
\hline Psychosis, not other specified (PNOS) & $12(3.2)$ \\
\hline Others & $16(4.3)$ \\
\hline \multicolumn{2}{|l|}{ Substance use } \\
\hline No substance use & $177(47.2)$ \\
\hline Any substance use & $198(52.8)$ \\
\hline Alcohol & $136(36.3)$ \\
\hline Stimulants & $124(33.1)$ \\
\hline Marijuana & $96(25.6)$ \\
\hline
\end{tabular}

than females. Younger age, compared to older age, also significantly increased the risk of marijuana use by 3.6 times ( $95 \%$ CI: $1.72,7.48)$.

\section{Discussion}

This study examined predictors of alcohol, stimulant, and marijuana use by Asian Americans with psychiatric disorders in residential treatment programs. The prevalence of co-occurring substance use was about 53\% in Asian Americans with mental disorders. Binary logistic regression analyses revealed that male gender, older age, and depressive disorder predicted more alcohol use, but homelessness and schizophrenia predicted less alcohol use. Male gender, homelessness, and smoking predicted more stimulant use. Male gender and younger age predicted more marijuana use. 
Table 2. Binary logistic regression analyses for variables predicting alcohol, stimulants, and marijuana use $(N=375)$.

\begin{tabular}{|c|c|c|c|c|c|c|}
\hline \multirow{2}{*}{ Variable } & \multicolumn{6}{|c|}{ Table Column Head } \\
\hline & $B$ & S.E. & Wald $(d f=1)$ & $O R$ & $L L$ & $U L$ \\
\hline \multicolumn{7}{|l|}{ Alcohol use } \\
\hline Younger age $^{\mathrm{a}}$ & -1.12 & 0.40 & $7.78^{\star \star}$ & 0.33 & 0.15 & 0.72 \\
\hline Middle age $\mathrm{e}^{\mathrm{a}}$ & -0.80 & 0.38 & $4.46^{*}$ & 0.45 & 0.21 & 0.94 \\
\hline Male & 1.69 & 0.33 & $25.91^{\star * *}$ & 5.42 & 2.83 & 10.40 \\
\hline Homelessness & -0.97 & 0.32 & $9.19^{* *}$ & 0.38 & 0.20 & 0.71 \\
\hline Smoker & 0.41 & 0.33 & 1.61 & 1.51 & 0.80 & 2.87 \\
\hline Schizophrenia & -1.53 & 0.37 & $17.59^{* * *}$ & 0.22 & 0.11 & 0.44 \\
\hline $\begin{array}{c}\text { Depressive disorder } \\
R^{2}=0.31-0.43\end{array}$ & 1.67 & 0.42 & $16.30^{* * *}$ & 5.33 & 2.37 & 12.01 \\
\hline \multicolumn{7}{|l|}{$\chi^{2}(d f)=121.04(7)^{\star * *}$} \\
\hline \multicolumn{7}{|l|}{ Stimulant use } \\
\hline Younger age $^{\mathrm{a}}$ & 0.78 & 0.40 & 3.77 & 2.17 & 0.99 & 4.75 \\
\hline Middle age ${ }^{\mathrm{a}}$ & 0.16 & 0.39 & 0.18 & 1.18 & 0.55 & 2.51 \\
\hline Male & 1.87 & 0.32 & $34.85^{\star \star *}$ & 6.49 & 3.49 & 12.07 \\
\hline Homelessness & 1.51 & 0.34 & $19.78^{* * *}$ & 4.53 & 2.33 & 8.81 \\
\hline Smoker & 1.02 & 0.37 & $7.39^{* *}$ & 2.76 & 1.33 & 5.74 \\
\hline Schizophrenia & 0.51 & 0.35 & 2.14 & 1.66 & 0.84 & 3.28 \\
\hline SAD & 0.39 & 0.40 & 0.93 & 1.47 & 0.67 & 3.26 \\
\hline \multicolumn{7}{|l|}{$R^{2}=0.24-0.34$} \\
\hline \multicolumn{7}{|l|}{$\chi^{2}(d f)=88.54(7)^{\star \star *}$} \\
\hline \multicolumn{7}{|l|}{ Marijuana use } \\
\hline Younger age $^{\mathrm{a}}$ & 1.28 & 0.38 & $11.58^{\star *}$ & 3.59 & 1.72 & 7.48 \\
\hline Middle age ${ }^{\mathrm{a}}$ & 0.41 & 0.40 & 1.14 & 1.52 & 0.70 & 3.31 \\
\hline Male & 2.13 & 0.32 & $43.63^{* * *}$ & 8.44 & 4.48 & 15.90 \\
\hline Bipolar disorder & -20.27 & 5648.89 & 0.00 & 0.00 & 0.00 & 0.00 \\
\hline $\begin{array}{l}\text { Other psychiatric } \mathrm{dx} \text {. } \\
\qquad R^{2}=0.26-0.38\end{array}$ & 0.56 & 0.56 & 1.01 & 1.75 & 0.59 & 5.20 \\
\hline$\chi^{2}(d f)=113(5)^{\star * \star}$ & & & & & & \\
\hline
\end{tabular}

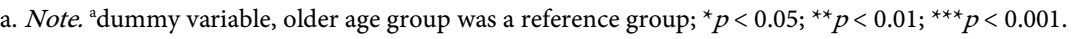

Most findings from this study were consistent with those from other studies [10] [20] [24] except for the association between age and alcohol use. In this study, older age ( $>50$ years old) indicated an increased risk of alcohol use, which is inconsistent with findings from another study that showed higher alcohol use with younger age [9]. Due to characteristics of the study's settings, the residential treatment programs being located in the San Francisco Bay area with a higher number of homeless people, about $40 \%$ of this study's sample was homeless. Findings from this study revealed that homelessness significantly increased the risk of stimulant use, which is consistent with findings from another study and well supported since people with unstable housing conditions are highly vulnerable to substance use further leading to aggravated mental symptoms [25].

In this sample of Asian Americans, schizophrenia and schizoaffective disorder were major psychiatric diagnoses, whereas depressive disorder and bipolar disorder were much less common compared to other race/ethnic groups from other studies [26] [27] [28]. This may be related to underrepresented reports for and a 
lower mental health service utilization for their mood disorders among Asian Americans. In accordance with findings from other studies, this study also found a lower prevalence of substance use among Asian Americans [6] [15] [29]. It is also possible that the higher proportion of patients with schizophrenia and schizoaffective disorder in this study is associated with lower rates of substance use due to a limited access to substances [16] [17]. Although schizophrenia was found to be a protective factor of substance use in this study as well as in other studies [18], having psychiatric disorders such as depression and anxiety is generally considered to increase vulnerability to substance use. Specifically, anxiety patients may seek drugs such as marijuana to relieve their anxious or depressive symptoms as a coping mechanism [30]. These self-medicating behaviors may be more common among untreated patients with underlying psychiatric disorders, and in turn, co-occurring substance use can aggravate the severity of their psychiatric symptoms [31]. In this study, however, the relationship between anxiety and more alcohol, stimulant, and marijuana use was unable to support this explanation due to the very low rate of anxiety disorder among Asian Americans.

It is obvious that co-occurring substance use leads to difficult psychiatric treatment, higher treatment costs, and longer hospital stays [32] [33] [34]. Studies have shown that substance users receiving care for their substance use showed decreased depressive symptoms [35] and integrated treatment programs improved patients' psychiatric symptoms [36]. Although co-occurring substance users are considered a highly vulnerable population, treatment services such as psychiatric outpatient visits and substance abuse treatment programs are still inadequately used [37] [38] [39]. Especially for Asian Americans, there may be other potential issues regarding the underutilization of mental health services such as lower English proficiencies, stigma around having or being diagnosed with psychiatric disorders, cultural beliefs about receiving psychiatric care, limited access to health care services, and discrimination within health care systems [40] [41]. Therefore, these barriers should be addressed in health care systems and efforts should be made to increase access to psychiatric mental health services for Asian Americans at individual, community, and policy levels.

\section{Study Limitations}

This study used a cross-sectional design to examine predictors of co-occurring alcohol, stimulant, and marijuana use of Asian Americans with psychiatric disorders receiving residential treatment services; therefore, a causal relationship cannot be assumed. The sample of this study came from residential treatment programs only in the San Francisco Bay area where Asian Americans and the homeless are overrepresented, resulting in a limited representation of the US population. In addition, this study did not examine Asian subgroup differences in the prevalence of and risk factors of substance use; therefore, it may overlook important factors such as levels of acculturation, length of residence in the US, and immigration generation [8] [42]. Variables reflecting socioeconomic status such as income level and current or past job which are possible risk factors of 
psychiatric disorders and substance use [23] were not included in this study because most participants were homeless due to their lower level of functioning related to their psychiatric disorder prognosis. This study's sample was mostly diagnosed with severe psychiatric disorders such as schizophrenia and schizoaffective disorder, which may have led to biased findings. Lastly, findings from this study indicated that there may be patterns of polysubstance use among Asian Americans with psychiatric disorders; however, this study did not look at the prevalence of and risk factors of polysubstance use, indicating the need for future research study.

\section{Conclusion}

This study found that the prevalence of co-occurring substance use was significantly high among Asian Americans with mental disorders in residential treatment programs. Therefore, strategies to manage co-occurring substance use should include increasing awareness about co-occurring substance use problems of ethnic minority psychiatric clients, early identification of risk groups, and the development and implementation of appropriate prevention and treatment programs for high-risk groups at the local, state, and federal level.

\section{Acknowledgements}

The authors would like to acknowledge Michelle Grace Lee, an undergraduate research assistant in the School of Nursing, San Diego State University, for her manuscript editing.

\section{Conflicts of Interest}

The authors declare that they have no competing interests.

\section{Funding}

This study was not funded by any institution or body.

\section{Authors' Contributions}

MK developed the study design, performed data collection \& analysis, and drafted the manuscript. JL and MN performed literature review and data collection. LC supervised overall study and reviewed the manuscript. All authors read and approved the final manuscript.

\section{References}

[1] Humes, K.R., Jones, N.A. and Ramirez, R.R. (2011) Overview of Race and Hispanic Origin: 2010: 2010 Census Briefs. https://www.census.gov/prod/cen2010/briefs/c2010br-02.pdf

[2] Chen, H.J. (2005) Mental Illness and Principal Physical Diagnoses among Asian American and Pacific Islander Users of Emergency Services. Issues in Mental Health Nursing, 26, 1061-1079. https://doi.org/10.1080/01612840500280729

[3] Substance Abuse and Mental Health Services Administration (SAMHSA) (2017) 
Key Substance Use and Mental Health Indicators in the United States: Results from the 2016 National Survey on Drug Use and Health (HHS Publication No. SMA 17-5044, NSDUH Series H-52). Center for Behavioral Health Statistics and Quality, Substance Abuse and Mental Health Services Administration, Rockville.

https://www.samhsa.gov/data/

[4] Unick, G.J., et al. (2011) Factors Affecting Psychiatric Inpatient Hospitalization from a Psychiatric Emergency Service. General Hospital Psychiatry, 33, 618-625. https://doi.org/10.1016/j.genhosppsych.2011.06.004

[5] Lim, S., Kasprow, W.J. and Rosenheck, R.A. (2006) Psychiatric Illness and Substance Abuse among Homeless Asian-American Veterans. Psychiatric Services, 57, 704-707. https://doi.org/10.1176/ps.2006.57.5.704

[6] Xu, Y., et al. (2011) Twelve-Month Prevalence of Psychiatric Disorders and Treatment-Seeking among Asian Americans/Pacific Islanders in the United States: Results from the National Epidemiological Survey on Alcohol and Related Conditions. Journal of Psychiatric Research, 45, 910-918.

https://doi.org/10.1016/j.jpsychires.2010.12.009

[7] Niv, N., Wong, E.C. and Hser, Y.I. (2007) Asian Americans in Community-Based Substance Abuse Treatment: Service Needs, Utilization, and Outcomes. Journal of Substance Abuse Treatment, 33, 313-319. https://doi.org/10.1016/j.jsat.2006.12.012

[8] Appel, H.B., Huang, B., Ai, A.L. and Lin, C.J. (2011) Physical, Behavioral, and Mental Health Issues in Asian American Women: Results from the National Latino Asian American Study. Journal of Women's Health, 20, 1703-1711. https://doi.org/10.1089/jwh.2010.2726

[9] Toleran, D.E. (2012) Substance Use among Chinese, Filipino, and Vietnamese Adult Men Living in San Jose, Daly City, and San Francisco, and Its Implications on ATOD Prevention Services. Journal of Ethnicity in Substance Abuse, 11, 86-99. https://doi.org/10.1080/15332640.2012.652534

[10] Iwamoto, D., Takamatsu, S. and Castellanos, J. (2012) Binge Drinking and Alcohol-Related Problems among US-Born Asian Americans. Cultural Diversity \& Ethnic Minority Psychology, 18, 219-227. https://doi.org/10.1037/a0028422

[11] Makimoto, K. (1998) Drinking Patterns and Drinking Problems among Asian-Americans and Pacific Islanders. Alcohol Health and Research World, 22, 270-275.

[12] Sakai, J.T., Ho, P.M., Shore, J.H., Risk, N.K. and Price, R.K. (2005) Asians in the United States: Substance Dependence and Use of Substance-Dependence Treatment. Journal of Substance Abuse Treatment, 29, 75-84. https://doi.org/10.1016/j.jsat.2005.04.002

[13] Chow, J. (2002) Asian American and Pacific Islander Mental Health and Substance Abuse Agencies: Organizational Characteristics and Service Gaps. Administration and Policy in Mental Health, 30, 79-86. https://doi.org/10.1023/A:1021231701732

[14] Park, S.Y., Shibusawa, T., Yoon, S.M. and Son, H. (2010) Characteristics of Chinese and Korean Americans in Outpatient Treatment for Alcohol Use Disorders: Examining Heterogeneity among Asian American Subgroups. Journal of Ethnicity in Substance Abuse, 9, 128-142. https://doi.org/10.1080/15332641003772660

[15] Mericle, A.A., Ta Park, V.M., Holck, P. and Arria, A.M. (2012) Prevalence, Patterns, and Correlates of Co-Occurring Substance Use and Mental Disorders in the United States: Variations by Race/Ethnicity. Comprehensive Psychiatry, 53, 657-665. https://doi.org/10.1016/j.comppsych.2011.10.002

[16] Chafetz, L., White, M.C., Collins-Bride, G. and Nickens, J. (2005) The Poor General 
Health of the Severely Mentally Ill: Impact of Schizophrenic Diagnosis. Community Mental Health Journal, 41, 169-184. https://doi.org/10.1007/s10597-005-2651-z

[17] Chafetz, L., White, M.C., Collins-Bride, G., Nickens, J. and Cooper, B.A. (2006) Predictors of Physical Functioning among Adults with Severe Mental Illness. Psychiatric Services, 57, 225-231. https://doi.org/10.1176/appi.ps.57.2.225

[18] Swendsen, J., et al. (2010) Mental Disorders as Risk Factors for Substance Use, Abuse and Dependence: Results from the 10-Year Follow-Up of the National Comorbidity Survey. Addiction, 105, 1117-1128. https://doi.org/10.1111/j.1360-0443.2010.02902.x

[19] McMillan, K.A., Enns, M.W., Asmundson, G.J. and Sareen, J. (2010) The Association between Income and Distress, Mental Disorders, and Suicidal Ideation and Attempts: Findings from the Collaborative Psychiatric Epidemiology Surveys. Journal of Clinical Psychiatry, 71, 1168-1175. https://doi.org/10.4088/JCP.08m04986gry

[20] Iwamoto, D., Liu, W.M. and McCoy, T.E. (2011) An Exploratory Model of Substance Use among Asian American Women: The Role of Depression, Coping, Peer Use and Asian Values. Journal of Ethnicity in Substance Abuse, 10, 295-315. https://doi.org/10.1080/15332640.2011.623494

[21] Cheng, A.W., Lee, C.S. and Iwamoto, D.K. (2012) Heavy Drinking, Poor Mental Health, and Substance Use among Asian Americans in the NLAAS: A Gender-Based Comparison. Asian American Journal of Psychology, 3, 160-167. https://doi.org/10.1037/a0028306

[22] Wong, F.Y., et al. (2007) Substance Use among a Sample of Foreign- and US-Born Southeast Asians in an Urban Setting. Journal of Ethnicity in Substance Abuse, 6, 45-66. https://doi.org/10.1300/J233v06n01_04

[23] Lee, Y.M. and Holm, K. (2012) Stressors Related to Depression among Elderly Korean Immigrants. Issues in Mental Health Nursing, 33, 52-58. https://doi.org/10.3109/01612840.2011.618965

[24] Bryant, A.N. and Kim, G. (2012) Racial/Ethnic Differences in Prevalence and Correlates of Binge Drinking among Older Adults. Aging \& Mental Health, 16, 208-217. https://doi.org/10.1080/13607863.2011.615735

[25] Palepu, A. (2012) Daily Substance Use and Mental Health Symptoms among a Cohort of Homeless Adults in Vancouver, British Columbia. Journal of Urban Health, 90, 740-746. https://doi.org/10.1007/s11524-012-9775-6

[26] Woodward, A.T. (2012) Prevalence of Lifetime DSM-IV Affective Disorders among Older African Americans, Black Caribbeans, Latinos, Asians and Non-Hispanic White People. International Journal of Geriatric Psychiatry, 27, 816-827. https://doi.org/10.1002/gps.2790

[27] Lee, S.Y., Martins, S.S., Keyes, K.M. and Lee, H.B. (2011) Mental Health Service Use by Persons of Asian Ancestry with DSM-IV Mental Disorders in the United States. Psychiatric Services, 62, 1180-1186. https://doi.org/10.1176/ps.62.10.pss6210_1180

[28] Asnaani, A., Richey, J.A., Dimaite, R., Hinton, D.E. and Hofmann, S.G. (2010) A Cross-Ethnic Comparison of Lifetime Prevalence Rates of Anxiety Disorders. The Journal of Nervous and Mental Disease, 198, 551-555. https://doi.org/10.1097/NMD.0b013e3181ea169f

[29] Evans, E., Pierce, J., Li, L., Rawson, R. and Hser, Y.I. (2012) More Alike than Different: Health Needs, Services Utilization, and Outcomes of Asian American and Pacific Islander (AAPI) Populations Treated for Substance Use Disorders. Journal of Ethnicity in Substance Abuse, 11, 318-338. https://doi.org/10.1080/15332640.2012.735172 
[30] Buckley, P.F. (2006) Prevalence and Consequences of the Dual Diagnosis of Substance Abuse and Severe Mental Illness. Journal of Clinical Psychiatry, 67, 5-9.

[31] Goldstein, B.I., Velyvis, V.P. and Parikh, S.V. (2006) The Association between Moderate Alcohol Use and Illness Severity in Bipolar Disorder: A Preliminary Report. Journal of Clinical Psychiatry, 67, 102-106. https://doi.org/10.4088/JCP.v67n0114

[32] Smith, M.J., Thirthalli, J., Abdallah, A.B., Murray, R.M. and Cottler, L.B. (2009) Prevalence of Psychotic Symptoms in Substance Users: A Comparison across Substances. Comprehensive Psychiatry, 50, 245-250. https://doi.org/10.1016/j.comppsych.2008.07.009

[33] Baker, A. (2002) Evaluation of a Motivational Interview for Substance Use within Psychiatric In-Patient Services. Addiction, 97, 1329-1337. https://doi.org/10.1046/j.1360-0443.2002.00178.x

[34] Dickey, B., Azeni, H., Weiss, R. and Sederer, L. (2000) Schizophrenia, Substance Use Disorders and Medical Co-Morbidity. Journal of Mental Health Policy and Economics, 3, 27-33. https://doi.org/10.1002/1099-176X(200003)3:1<27::AID-MHP67>3.0.CO;2-P

[35] Small, M. and Lewis, S. (2003) Six Month Follow-Up of Anxiety and Depression in Polysubstance Misusers Undergoing Treatment in a Therapeutic Community. Therapeutic Communities, 24, 142-160.

[36] Craig, T.K., et al. (2008) Integrated Care for Co-Occurring Disorders: Psychiatric Symptoms, Social Functioning, and Service Costs at 18 Months. Psychiatric Services, 59, 276-282. https://doi.org/10.1176/ps.2008.59.3.276

[37] Horsfall, J., Cleary, M., Hunt, G.E. and Walter, G. (2009) Psychosocial Treatment for People with Co-Occurring Severe Mental Illnesses and Substance Use Disorders (Dual Diagnosis): A Review of Empirical Evidence. Harvard Review of Psychiatry, 17, 24-34. https://doi.org/10.1080/10673220902724599

[38] Cleary, M., Hunt, G.E., Matheson, S., Siegfried, N. and Walter, G. (2008) Psychosocial Treatment Programs for People with Both Severe Mental Illness and Substance Misuse. Schizophrenia Bulletin, 34, 226-228. https://doi.org/10.1093/schbul/sbm165

[39] Verduin, M.L., Carter, R.E., Brady, K.T., Myrick, H. and Timmerman, M.A. (2005) Health Service Use among Persons with Comorbid Bipolar and Substance Use Disorders. Psychiatric Services, 56, 475-480. https://doi.org/10.1176/appi.ps.56.4.475

[40] Clough, J., Lee, S. and Chae, D.H. (2013) Barriers to Health Care among Asian Immigrants in the United States: A Traditional Review. Journal of Health Care for the Poor and Underserved, 24, 384-403. https://doi.org/10.1353/hpu.2013.0019

[41] Sue, S., Yan, C., Saad, C.S. and Chu, J.P. (2012) Asian American Mental Health: A Call to Action. The American Psychologist, 67, 532-544. https://doi.org/10.1037/a0028900

[42] Yeh, C.J. (2003) Age, Acculturation, Cultural Adjustment, and Mental Health Symptoms of Chinese, Korean, and Japanese Immigrant Youths. Cultural Diversity and Ethnic Minority Psychology, 9, 34-48. https://doi.org/10.1037/1099-9809.9.1.34 